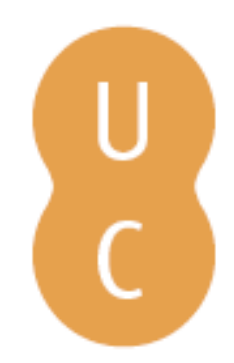

\title{
pommalina
}

\section{O velho e a pólis em Eurípides}
Autor(es):
Fialho, Maria do Céu
Publicado por: Imprensa da Universidade de Coimbra; Annablume
URL
persistente:
URI:http://hdl.handle.net/10316.2/40887
DOI:
DOI:https://doi.org/10.14195/978-989-26-1278-2_4

Accessed : $\quad$ 26-Apr-2023 11:58:00

A navegação consulta e descarregamento dos títulos inseridos nas Bibliotecas Digitais UC Digitalis, UC Pombalina e UC Impactum, pressupõem a aceitação plena e sem reservas dos Termos e Condições de Uso destas Bibliotecas Digitais, disponíveis em https://digitalis.uc.pt/pt-pt/termos.

Conforme exposto nos referidos Termos e Condições de Uso, o descarregamento de títulos de acesso restrito requer uma licença válida de autorização devendo o utilizador aceder ao(s) documento(s) a partir de um endereço de IP da instituição detentora da supramencionada licença.

Ao utilizador é apenas permitido o descarregamento para uso pessoal, pelo que o emprego do(s) título(s) descarregado(s) para outro fim, designadamente comercial, carece de autorização do respetivo autor ou editor da obra.

Na medida em que todas as obras da UC Digitalis se encontram protegidas pelo Código do Direito de Autor e Direitos Conexos e demais legislação aplicável, toda a cópia, parcial ou total, deste documento, nos casos em que é legalmente admitida, deverá conter ou fazer-se acompanhar por este aviso.

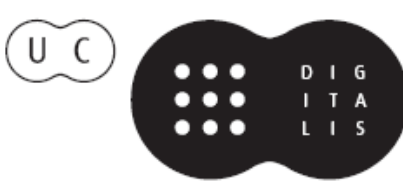




\section{O Livro do Tempo: Escritas e reescritas}

\section{Teatro Greco-Latino e sua recepção I}

Maria de Fátima Silva, Maria do Céu Fialho \& José Luís Brandão (coords.)

IMPRENSA DA UNIVERSIDADE DE COIMBRA

ANNABLUME 


\title{
O velho e a Pólis em Eurípides ${ }^{1}$ (Old men and the polis in Euripides)
}

\author{
Maria do CÉu Fialho (mcfialhofluc@gmail.com) \\ Universidade de Coimbra
}

\begin{abstract}
Resumo - Este capítulo pretende acompanhar a reflexão euripidiana sobre deveres e direitos dos velhos no oikos ateniense em tempo de extrema crise do oikos: a geroboskia, inspirada na lei natural da reciprocidade, não deve levar o velho a uma total passividade. Os laços de solidariedade devem ser mais fortes nesta pequena mas determinante comunidade. Assim, a decisão de auto-sacrifício de Alceste é uma decisão política que tem como objectivo manter vivo o senhor da casa e manter a salvo os filhos de ambos. Além disso, Alceste faz Admeto jurar que não fará entrar na casa uma nova esposa. São dados exemplos de outros velhos, em outras tragédias euripidianas, que compreenderam qual o seu papel em tempo de crise do oikos. Esta polémica abre espaço para uma reflexão crítica sobre o papel e estatuto do velho nas sociedades ocidentais contemporâneas.

Palavras-chave - Velhos, geroboskia, reciprocidade, solidariedade, Eurípides, sociedades contemporâneas.
\end{abstract}

Aвstract - This chapter aims to follow Euripides' reflexion about duties and rights of old people in the Athenian oikos in a time of extreme crisis in the oikos: the geroboskia, inspired in a natural law of reciprocity, shall not lead old people to a total passivity. Ties of solidarity must be stronger in this small but determinant community. In this way, Alcestis' decision of self-sacrifice is a political decision in order to keep alive the house kyrios and keep safe their children. Besides Alcestis makes Admetos swear that he will never bring a new wife to the house. Examples of old men who understood their role under crisis circumstances are to be seen in other Euripides' tragedies. This polemic opens space to a critical reflexion on the role and the status of old people in contemporary western societies.

Keywords - Old people, geroboskia, reciprocity, solidarity, Euripides, contemporary societies.

Com o envelhecimento da população nos países ditos desenvolvidos, na actualidade, e a queda demográfica, o velho passou a ser centro da polémica sobre o modo possível e conveniente da sua presença na comunidade. Com isso, converteu-se em pólo de tensões, verbalizadas ou silenciosas.

\footnotetext{
${ }^{1}$ Este trabalho representa os resultados de investigação feita no âmbito das actividades da UI\&D-CECH (projeto UID/ELT/00196/2013), desenvolvendo, com posterior reflexão e leitura sobre um tema que me é caro e me tem ocupado, em correlação com a expressão trágica dos paradoxos do oikos e da sociedade ateniense em tempo de crise, um aprofundamento e amplificação do publicado em Fialho 2010: 108-121.
} 
A crise sistémica que se faz sentir, o desemprego, a diminuição da população jovem e activa profissionalmente, decorrente da emigração e já das consequências que se vão fazendo sentir da baixa demográfica, instalaram uma situação de ruptura iminente dos mecanismos da Segurança Social e causam, até, sérios problemas à eficácia e suportabilidade do Serviço Nacional de Saúde. O neoliberalismo desenfreado, que vai ganhando mais adeptos e que tem, entre nós, acérrimos defensores, instala, no espaço público e nas mentalidades, entre outros binómios de conflito, um confronto geracional jovens/velhos, em que estes são vistos como um fardo de despesa crescente, por via das pensões de reforma e dos cuidados de saúde que com eles são gastos.

No entanto, ainda por via da crise, a política de restrição de pensões e do acesso a cuidados públicos tem relegado a geração sénior, em alguns sectores, para uma situação de pobreza que leva a que as pensões auferidas não cubram as despesas mínimas para uma vida de qualidade. Também a dispersão familiar, com a necessidade de mobilidade em função de condições de trabalho, ou o próprio ritmo do dia-a-dia, ou ainda a mentalidade que se vai instalando, inclusivamente entre familiares, relega muitos membros desta humanidade envelhecida para o abandono, a carência, a solidão. Tal situação levou a que o Estado se visse obrigado, recentemente, a criar legislação, no âmbito do Direito de Família, chamando à responsabilidade os descendentes. Podem os velhos, hoje em dia, ainda que raramente accionem tal processo (porventura nem o conhecem), denunciar judicialmente o abandono pelos filhos, de modo a que estes sejam chamados à responsabilidade.

Saídos dos tempos áureos do Estado providencial, esse mesmo Estado, já não providência, conduz a uma situação institucionalizada, ainda que timidamente, que, sem que porventura tome consciência disso, nos reaproxima dos Gregos: o dever, ainda que in extremis, de geroboskia. Pelo caminho perdeu-se, no entanto, muito da noção de dignidade, da justa ocupação, pela velhice, de um lugar na sociedade e da necessária interacção com esta geração que representa uma etapa natural, para a qual todos tendemos, na vida humana. O velho é um fardo que há que suportar, por ter já cumprido o seu papel? Também aí se desvela um outro componente sócio-económico a tornar mais complexa a situação: são incontáveis, entre nós, os casos em que o desemprego familiar, que atinge os dois elementos do casal, chama pais e avós a ajudar, com as suas pensões diminuídas, a família em crise económica e a providenciar sustento e garantir a educação dos netos. À luz da conceptologia grega, assistiríamos, pois, num contexto de crise e de excepção, a uma paidotrophia espontânea e renovada que gera uma interaç̧ão de solidariedade entre as gerações diversas de uma família.

Para um classicista, toda esta complexa trama torna óbvia a actualidade e a pertinência de pensar com os Gregos estes nexos, estipulados pela lei mas que a ética de tempos de crise leva a reler e a reinventar. Logo à partida se percebe que, para o homem grego, estes nexos são absolutamente naturais e fazem parte 
de um todo mais vasto. É que, para o Grego, o modelo do ciclo da vegetação, cujos espécimes nascem, crescem até deixar amadurecer a semente, para em seguida morrerem ou serem colhidos e deixarem, todavia, a semente a partir da qual se desenvolverão novos rebentos, idênticos aos anteriores, constitui o pressuposto da perspectiva aristocrática da physis humana inata e imutável, adequada à perpetuação². O símile homérico das folhas das árvores (Il. 6. 144-149), que aproxima as gerações dos mortais, no seu renovar incessante, à incessante renovação das folhas, exprime essa antiquíssima percepção.

Esta referência cruza com uma outra, pertencente ao domínio do mundo animal: a de vida, viabilizada e sustentada pelo alimento, boskema ou trophe. Se a renovação vegetal se rege pelo ritmo da circularidade, o sustento das jovens crias pelos seus progenitores rege-se pela força do instinto - o da sobrevivência da espécie e o da sobrevivência própria. O símile das folhas das árvores suporta a aproximação do mundo animal ao vegetal; a imagem recorrente da terra como a mãe que alimenta homens e animais completa esta aproximação no sentido inverso ${ }^{3}$. Por sua vez, a noção de geração activa, no que toca aos humanos, e a passagem da herança da physis para os filhos engendrados são entendidas, ainda na época clássica, entre os Gregos, como capacidade do homem, não da mulher - ainda que a tragédia nos venha apresentar momentos de problematização e questionamento desta perspectiva. É topos corrente o da comparação do progenitor ao lavrador, que prepara a terra e deita a semente, e da mãe à terra fecundada, cujo papel se limita a nutrir a semente, para que esta germine ${ }^{4}$.

A evidência das leis que regem a natureza e a vida, que abrangem o homem como partícula pensante do universo, revestem-se, para o Grego, da força de 'leis não escritas', agrapta nomima, primordiais e anteriores a qualquer normativização específica do edifício social. Mais ainda: na medida em que o homem pertence a esse mesmo universo e está sujeito a essas leis, elas constituem a verdadeira fonte inspiradora do direito positivo na comunidade humana ideal, que pretende manter-se em consonância com a ordem global de um cosmos regido por uma Justiça de dimensão sagrada ${ }^{5}$.

O elo de vida e de pertença natural que une progenitores e progénie, no reino animal, e que se traduz fisicamente na provisão de alimento e de cuidados, é, por sua vez, não só observado pelo homem como convertido numa espécie de campo de projeç̧ão da própria expectativa humana. Isto é, ao idealizar o

\footnotetext{
${ }^{2}$ O modelo do ciclo vegetal que subjaz à percepção e conceptualização da physis grega foi admiravelmente identificado e analisado pelo eminente filólogo Patzer 1945.

${ }^{3}$ Lembremos o epíteto da terra da Ftia: botianeira, 'a que alimenta os homens' (Il. 1. 155). A. Sept. 16; veja-se, também, e.g., A. Ch. 66, P1. Tim. 40b.

${ }^{4}$ Veja-se, a título de exemplo, A. Eu. 657-666; S. Tr. 31-35.

5 Fialho 2010: 108-109. Concorda com esta perspectiva Cantarella 2015. Refere tal visão Damet 2015.
} 
comportamento animal que observa, o homem projecta nele as expectativas que cria sobre uma sociedade humana ideal e atribui à força do instinto animal o que, em boa verdade, constitui uma expectativa de carácter ético-social sobre a própria praxis humana em sociedade. Assim se cria a convicção, visível em textos poéticos desde cedo, de que há, entre os animais da mesma espécie e da mesma linhagem, uma praxis natural de retribuição das crias alimentadas e protegidas para com os progenitores que as alimentaram e protegeram, quando a idade os enfraquece e fragiliza.

Aristófanes, nas suas Aves (1353-1357), põe na boca de Pistetero a referência a uma "lei antiga, que consta dos kyrbeis das cegonhas e que diz: quando o pai cegonha tiver alimentado as crias até as deixar aptas a voar, é obrigação dos filhos, por sua vez, alimentar o pai”. Igual princípio é formulado pelo Coro de Jovens de Micenas, na primeira estrofe do estásimo III da Electra de Sófocles ${ }^{6}$ :

Porque é que nós, vendo as aves lá no alto, as mais dotadas de senso, a procurarem sustento para aqueles de quem nasceram, de quem receberam cuidados, não pagamos de igual modo tais desvelos? Não, pelo raio de Zeus, por Témis, que toma assento lá nos céus, eles não irão ficar por muito tempo isentos de castigo.

Quanto à avaliação do velho constata-se que, da épica à elegia e à lírica, foram os Gregos verbalizando, ora a compensação que a natureza proporciona ao ancião - menos força mas mais sabedoria, mais experiência e competência retórica (lembremos o símile das cigarras, Il.3); lembremos a figura de Nestor, de fluidos e extensos discursos, em palavras doces como o mel, (ainda que este não se exima ao combate nem se queixe de fraqueza física). Sólon, por sua vez, reconhece a dinâmica de aprendizagem propiciada pela experiência e pelo envelhecimento (fr. 18 West) ${ }^{7}$ mas, simultaneamente, entende a pertinência e necessidade de legislar sobre a qualidade de vida dos velhos, dando enquadramento legal ao dever ético dos filhos zelarem pelo sustento e apoio de quem os gerou e criou: a geroboskia é assim apresentada num processo de reciprocidade quanto à paidotrophia, e a sua infracção sujeita a penalização do filho no espaço público.

$\mathrm{O}$ que o homem grego pensa ser realidade entre os animais, particularmente entre as aves, como expressão de uma lei natural que se exerce na sua pureza - leitura que tem, afinal, na sua raiz, um processo de compreensão antropomórfica, idealizante, do comportamento animal - passa a ser tomado como exemplo reforçado de uma axiologia ética que deve reinar entre os homens, na comunidade organizada e na unidade basilar dessa comunidade - a casa, o oikos. O princípio da reciprocidade é suporte dessa axiologia.

\footnotetext{
${ }^{6}$ Concordo com o comentário de Kells ao estásimo, 1993: 178-179. Veja-se também Fialho 1992: 165-166.

7 Veja-se Leão-Rhodes 2015 e o seu comentário ao fragmento.
} 
Essa deve ser uma fonte poderosa do direito positivo a que o legislador dá forma, entendendo fazê-lo em consonância com o direito natural, voz da própria ordem cósmica, que, ironicamente, parece não falar suficientemente alto entre os homens - daí a necessidade da legislação de Sólon ${ }^{8}$. Já Lísias, nascido em meados do séc. V, clama, na sua diatribe contra Agorato (13. 91), que um varão que agrediu o pai biológico, lhe negou meios de subsistência e defraudou o pai adoptivo merece a mais severa das penas previstas pela lei: a morte. Lísias entende que tais actos se inscrevem no âmbito específico coberto pela graphe kakoseos".

E outros exemplos de discursos judiciais se lhe poderiam juntar, como o do discurso Contra Timarco (1. 28), em que Ésquines invoca a proibição, prevista pelo legislador, de os cidadãos de vida indigna falarem em público. Como exemplo de vida indigna cita a daqueles que infringem o dever de geroboskia ou os que chegam mesmo ao extremo de maltratar os pais. Seguindo o raciocínio que atribui ao legislador, pergunta também: “... pois se um homem falha em relação àqueles a quem deve honrar como deuses, como pode ele ...proceder em relação a estranhos e a toda a cidade?".

O raciocínio de Ésquines, já presente anteriormente em Lísias (31. 21-23), demonstra como o procedimento de um cidadão, no contexto do seu próprio oikos, se reveste de uma dimensão política na medida em que ilustra as potencialidades, neste caso negativas, do seu comportamento no contexto mais vasto da pólis. Movemo-nos, obviamente, num universo de direitos e deveres exclusivamente masculinos. A ilação extraída por Ésquines a partir do padrão de comportamento de Timarco em relação a membros do seu oikos, especificamente ao seu pai, sobre o padrão de comportamento a esperar de Timarco para com estranhos e para com a pólis, parte do pressuposto - real - de que o varão senhor do oikos, o seu kyrios, é o integrador daquele na pólis, aquele que representa a 'casa', no sentido lato, à luz da comunidade. A sua acção exerce-se como regulador, dentro e fora da casa, no pleno exercício dos seus deveres e direitos de cidadão, com participação activa na vida da pólis e das suas instituições. Assim

${ }^{8}$ Hunter 1994 dedica o cap. IV do seu livro à lei ateniense, em particular no que diz respeito ao dever de os filhos proporcionarem sustento e segurança aos seus pais, na velhice, ou a outros parentes idosos que os tenham substituído. $O$ incumprimento de tais normas, inspiradas pelo direito natural e regulamentadas pelo direito positivo, dava azo à denúncia pública e ao vexame de um castigo, por chicotadas, na praça pública. A matéria destas infracções constitui assunto de defesa ou acusação nos oradores áticos dos sécs. V e IV a. C. O legislador Sólon, no entanto, previu limites ao dever de gerotrophia: assim, bastardos, filhos de prostitutas, estavam dispensados de tal obrigação. O mesmo acontecia para aqueles filhos a quem os pais não haviam ensinado qualquer profissão, entendendo-se que tais pais não proporcionaram aos filhos a 'enxada' para que ganhassem o seu pão e o dos seus (frs. 56, 57R). $\mathrm{O}$ princípio da reciprocidade é, aqui, exercido pela negativa: sobre esta norma veja-se Leão 2001: 374-375. Veja-se também Stroud 1979: 5 a propósito da origem desta lei e da legislação soloniana.

${ }^{9}$ Veja-se Hunter 1994: 125. 
sendo, é dele, como filho varão, não da mulher, que a lei espera o cumprimento do dever de geroboskia em relação aos pais, na velhice.

À mulher está, antes, reservado o espaço do interior da casa, limitado o contacto com estranhos a ela. Como cidadã, dela se espera que contribua, enquanto terra fértil, para a continuidade do oikos a que pertence. Nesse sentido, ela alimenta a infância de seus filhos, até estes atingirem aquele estádio de iniciação, se de filhos varões se tratar, de vida no espaço público, pela educação fora da casa.

Pertence à própria natureza da tragédia dramatizar, pelo mito, situações de ruptura, de paradoxo na existência humana que ofereçam ao espectador uma reflexão e uma compreensão possível da sua vivência temporal e da sua condição, marcada pela finitude, de que a velhice é anúncio. Já Aristóteles verifica a escolha preferencial, por parte da tragédia ática, de um número restrito de famílias da mitologia para equacionar dramaticamente essa experiência de limitação humana. A preferência tem a ver com o facto de tais constelações familiares serem bem conhecidas pelo público ateniense, de modo a permitir que esse público se não distraísse da acção com a apresentação de figuras centrais absolutamente novas. Era fulcral o conhecimento prévio da estrutura e das distorções existentes na constelação daquele oikos, já que o entendimento que o homem grego tem da sua radicação no mundo, até ao final da época clássica, é, essencialmente, o de ser-no-oikos.

Por essa via se enquadrava como ser-na-pólis, já que o primeiro constituía o elemento-base de constituição da segunda. Assim se compreende que o conflito trágico tem sempre, no seu contexto primordial - ao contrário do que poderá vir a acontecer na história da recepção estética da tragédia, eventualmente de pendor individualizante, ou, mesmo, de posteriores entendimentos, epocalmente marcados, do teatro grego - uma dimensão política no sentido literal do termo, pois, ser-no-oikos significa já ser-na-pólis. Os paradoxos e rupturas dramatizados na vida do homem, no contexto do seu oikos, representam, simultaneamente, paradoxos e rupturas que afectam a segurança dos próprios fundamentos da pólis, que opõem ou excluem mesmo o indivíduo e a sua casa da ordem política, para a qual representam uma ameaça. É essa ameaça e a fragilidade insuspeitada de laços que parecem absolutamente firmes que põe em risco, simultaneamente, o sentido da acção humana e a estabilidade do cosmos em que o homem vive como o único zoon politikon.

Um dos aspectos que se prestam ao tratamento trágico, em algumas dessas constelações mitológicas, é precisamente o de distorções extremas na relação familiar, nas quais a quebra do princípio da reciprocidade de deveres entre gerações está presente e desempenha uma função importante. $O$ fulcro dessa reciprocidade toma a forma de dever (não cumprido) de proteç̧ão da vida, a que se liga o elemento essencial para a manutenção desta — o alimento. Refiro-me à correlação paidotrophia/geroboskia, que, para o espectador da tragédia ática, tinha 
não só o carácter de um imperativo ético, em consonância com as leis da natureza e o direito natural, como se viu, mas também a força de uma lei ancestral.

Todavia, a correlação deveres/direitos nem sempre é linear e sincopada no tempo, cessando uns para dar lugar aos outros. Creio que sobre esta questão se interrogou Eurípides, reiteradamente, através da sua narrativa dramática, começando em Alceste, representada em 438. A questão da gerotrophia, como expectativa criada nos progenitores, em Feres e sua esposa, toma a forma de uma exigência cega, baseada no antigo dever cumprido de alimentar o filho, a que se junta o apego à breve existência que ainda lhes resta, na velhice. Feres fala da vida que ainda tem à sua frente como um prazer a que tem direito, inalienável (690 sqq.) - palavras que, certamente, o espectador ateniense captaria como uma cega ironia, já que o topos do peso da velhice vem de longe, na poesia grega, e inundará a tragédia até à última das que até nós chegaram: Édipo em Colono (1211-1248).

A cegueira de Feres, insensível a todo o instinto de solidariedade que une membros de uma casa e gerações do mesmo sangue, leva-o a entender a cadeia de physis baseada num princípio, esgotado no tempo, de alimentar os descendentes, e no direito, sem barreiras nem restrições, de exigir sustento e manutenção, mesmo que o preço seja o da própria desagregação do oikos. $\mathrm{O}$ extremo individualismo da sua velhice, fechada nela própria, sem abertura ao futuro da sua própria casa, permite a chocante formulação, perante um Admeto arcado pelo luto e pelo desespero da perda de Alceste (685-686):

Pois é para ti mesmo, feliz ou infeliz, que tu nasceste.

A relação pai-filho, com toda a problemática de direitos e deveres, à luz da lei ateniense e dos exageros possíveis de quem espera, da lei, o seu cumprimento literal, sem entender razões mais fortes, que são as da própria natureza, não constitui exactamente o tema central da peça - serve-lhe, contudo, de horizonte. Nesse horizonte será Admeto levado a adquirir uma nova consciência da constelação de limitações, de valores e de afectos que suportam o oikos de que é kyrios.

Este drama, que toma como pressuposto a inevitável ameaça de morte que impende sobre o senhor do oikos, Admeto, com as consequências catastróficas que tal morte implica para esse mesmo oikos, abre com a proximidade da morte de Alceste, a esposa que àquele se substitui na morte. Aparentemente, o oikos está a salvo, mas o sacrifício desta mulher vem, inesperadamente, pôr a nu as fragilidades desse mesmo oikos, uma vez esvaziado da presença feminina. A salvo ficou a existência do seu kyrios. E que restou dessa célula social a que ele confere coesão e consistência? Que insuspeitadas realidades afloram à evidência com a morte de Alceste, denunciado o quanto é relativa essa lógica social de sucessão masculina, perpetuada por uma cadeia de deveres e direitos dentro da casa, quando levada à última instância? 
Consoante o refere Lesky ${ }^{10}$, Eurípides alterou um motivo próprio do conto popular, que Frínico e Ésquilo também haviam tratado, e deu-lhe outras características. $\mathrm{O}$ que aparentemente representa uma solução, ainda que dolorosa, para um problema na casa de Admeto - a ameaça iminente da morte do seu kyrios - converte-se no início de outros males que levam até uma avaliação mais profunda do próprio sentido e fundamento do oikos. Diria que a presença da morte no oikos constitui o núcleo a partir do qual as tensões se geram, a partir do qual as dimensões do afecto humano se revelam fundamentais para conferir sentido à própria existência humana no contexto da estrutura social. Eurípides quis sublinhar as implicações catastróficas da desarticulação do oikos pela perda de um dos seus elementos e, simultaneamente, pelo esvaziamento de relações entre gerações, em que o sentido de philia se perdeu. Em contrapartida, revela-se uma poderosa força de relações de philia com estranhos ao oikos. Um dos meios expressivos que o dramaturgo utiliza para tal é precisamente a frequência de termos do âmbito semântico de 'casa': oikos/ domal stege/ melathron ${ }^{11}$ combinada com o uso recorrente de philia/ philos e xenos ${ }^{12}$.

Como nota Goldfarb ${ }^{13}$, os termos philia/ philos ocorrem, sobretudo, associados a laços familiares. Mas com a personagem Héracles, no seu gesto de gratidão por uma hospitalidade que ultrapassou os limites do mero dever, a philia revela-se como uma força poderosa que pode unir estranhos, na sequência da gratidão de um xenos que, na fase final da peça, reconduz ao oikos a mãe e a esposa perdidas, elemento essencial para a recuperação da felicidade e harmonia. Nesta vivência de morte e de perda o jovem Eumelo chora a sua situação de philas monostolos te matros (406-407) e exclama, perante o cadáver da mãe (415): ololen oikos, "a casa acaba de morrer".

Os laços de philia, no contexto familiar de Alceste, implicam não só laços de sangue mas uma solidariedade decorrente dessa ligação de sangue, que dá consistência à família e à casa. É bem visível essa relação, traduzida expressivamente em palavras, entre Alceste e Admeto, de Alceste em relação aos filhos e, até, entre o Coro de Cidadãos e a casa de Admeto. A ausência de outros philoi, que como tal se manifestassem, levou Alceste ao sacrifício da sua vida por Admeto: é que o kyrios da casa é o garante da sua estabilidade, da sua prosperidade e da sua perpetuação. Quanto aos pais deste, ele mesmo diz, utilizando uma dicotomia tão do gosto de Eurípides, que se revelaram "philoi em palavras, não em actos" (333). Na origem da decisão de Alceste o poeta entrevê muito mais que a abnegada oferta da sua vida de uma mulher apaixonada.

${ }^{10}$ Lesky 1972: 289-300.

11 Luschning 1992.

12 Goldfarb 1992, Thury 1988.

13 No seu artigo Goldfarb 1988: 110-112 nota que tanto o Coro como Admeto se referem a Alceste como philtata (e.g. 1133). 
Admeto é, pelo seu estatuto à luz da mentalidade e do direito grego, o kyrios da casa, a coluna que a suporta. Desaparecido o kyrios, um parente masculino terá de o substituir como protector e gestor da casa, cujos membros, até à maioridade de um dos filhos varões, àquele permanecem vinculados com o estatuto de epikleroi. Alceste é estrangeira (otbneios, 533), como o próprio Admeto o refere mais tarde a Héracles. Isto torna ainda mais precária a sua situação. Procurar, na ausência de um kyrios dentro da casa, a estabilidade própria através de novo casamento com outro homem da Tessália, deixaria fragilizada a situação dos filhos órfãos (282 sqq.).

O sacrifício da sua própria vida surge para Alceste como solução, em nome da estabilidade da casa e do futuro dos filhos, já que nenhum outro membro da família está disposto a sacrificar-se para preservar Admeto. Todavia, Alceste tem consciência, ainda nos seus últimos momentos, que lhe era possível "tomar um marido, consoante o quisesse, entre os Tessálios, e habitar, na realeza, uma casa próspera" (285-286). Esta seria a alternativa se Alceste tivesse, perante Admeto e a sua descendência, a mesma atitude, isenta de afecto e individualista, que Feres manifesta. Por isso mesmo, a preocupação pelo futuro de seus filhos acompanha Alceste até ao fim, fazendo prometer a Admeto que nunca daria uma madrasta à sua descendência (299 sqq.). Uma nova mulher traria filhos do novo casal e poria em perigo a própria vida dos filhos de Admeto e de Alceste. Os sogros, com a sua longa experiência de vida, devem saber que esse é o curso infelizmente habitual em casas ricas.

A própria Alceste denuncia o egoísmo dos sogros, já de idade avançada, como um comportamento antinatural, de abandono e traição dos laços da própria physis (290-292): s' ho physas che tekousa proudosan. É neste contexto que a tensão Admeto-Feres deve ser entendida. É neste contexto, também, que há que identificar as condições paradoxais que levarão Admeto a uma reorganização da sua visão de valores no oikos e de forças que, verdadeiramente, a este dão consistência. Uma vez morto Admeto, caso ninguém o tivesse substituído, que garantias daria Feres de regressar com zelo e energia à sua primitiva função de kyrios? A sua disposição e atitudes mostram que está longe de querer assumir de novo responsabilidades - chegou o seu tempo de desfrutar apenas das prerrogativas a que a sua idade e paternidade dão direito, como se, na vida, uma fosse a etapa de cumprir deveres e outra a de fruir de direitos, ainda que membro permanente da casa e da pólis. Estamos bem longe da realidade romana ${ }^{14}$, com a qual a retratada na tragédia contrasta. Como nota Cantarella, por contraste, "in Rome the authority of fathers over their sons (unless the father decided to emancipate them) did not end when the children reached the age of majority, but continued as long as the paterfamilias lived, whatever might be the age of his descendants".

\footnotetext{
14 Cantarella 2015: 1.
} 
Já o próprio Apolo, no prólogo, tinha sublinhado o quase total abandono de Admeto - "depois de ter procurado todos os philoi, à vez, nenhum encontrou, a não ser a esposa, nem sequer seu pai ou a sua velha mãe que o deu à luz, que estivesse disposto a morrer em seu lugar" (15-18). Esta expectativa frustrada e denunciada irá gerar um verdadeiro conflito geracional. É com o deflagrar desse conflito que a questão da legitimitade moral da geroboskia como direito universal e sem contrapartida de deveres surge. A tragédia da casa de Admeto é visível. Ela é atingida no seu cerne de vitalidade, de afectos, de garantia de continuidade e de segurança para os mais jovens. Cantarella regista, com toda a consistência, as consequências relacionais decorrentes da diferença entre a relação legal entre pai e filho no direito romano e no direito grego: em Roma era óbvio o conflito geracional entre um pai de poder perpetuado e filhos maiores, com vida cívica, política e militar; na Grécia, porém, a suavidade do poder paternal, que, com a idade, vai sendo transferido para o filho como novo kyrios do oikos, diluía tais conflitos ${ }^{15}$.

Todavia, esta pertinente comparação feita pela eminente classicista, leva a que se torne mais evidente um conjunto de interrogações levantadas por Eurípides na peça em apreço: não suscitará a atitude do ancião que se entende dispensado já de deveres, por via do seu estatuto etário, e apenas detentor de direitos que os mais novos hão-de respeitar e alimentar, a desestabilização do oikos e a possibilidade de conflitos geracionais, quando este oikos entra numa profunda crise, que a todos respeita e todos afecta?

Alceste constata a contradição: Feres e sua mulher tiveram um filho e são eles mesmos que recusam morrer pelo filho. Isto é, geraram vida, perpetuaram potencialmente a sua casa. Chegados à velhice, recusam garantir a vida do filho que geraram, quando nenhuma outra podem gerar agora. Centrados em si, serão certamente estes os anciãos que hão-de reclamar o direito de geroboskia da parte de uma vida que geraram mas não preservaram, fazendo, além do mais, perigar o oikos ${ }^{16}$. Também o Coro censura o comportamento destes progenitores, a quem aplica o dual schetlio (470), por oposição à reconhecida philia da esposa (473). Feres, movido por um primitivo impulso de valorização da existência pelo que lhe resta dela gozar - comer e beber por conta de quem outrora ele gerou e alimentou, como um investimento a longo prazo - chega ao ponto de, alterado, exclamar (683-684):

Pais morrerem pelos filhos?! Eis uma lei que nunca recebi dos meus antepassados nem da Hélade!

15 Cantarella 2015: 2.

16 Já Homero havia referido e louvado a harmonia num lar construído sobre a harmonia dos esposos e sobre a aliança por eles celebrada (e.g., Od. 6. 180-181). Ésquilo consagra a tal aliança como a fonte de benefícios e o alicerce da cidade: Eu. 213 sqq. 
Começa a tomar forma a pergunta: até onde vão os deveres de sangue dos progenitores em relação à descendência, já que os deveres da descendência parecem ser nítidos, estão consagrados na própria legislação e o estado ateniense exerce vigilância sobre o seu cumprimento? Maior pertinência ganha a pergunta, se se tiver em conta a própria solidariedade entre companheiros de luta, jovens e velhos, na batalha, ou a consciência dos guerreiros que, já desde o que a ancestral elegia guerreira sublinha, pela comunidade sacrificam as suas vidas. Lembre-se a elegia de Tirteu $\left(10\right.$ W. 13-20) ${ }^{17}$ :

Lutemos com ardor por esta terra, morramos por nossos filhos, sem pouparmos a vida.

Ó jovens, permanecei em combate ao lado uns dos outros, não comeceis com a fuga vergonhosa ou com o medo, mas criai no vosso espírito um ânimo excelso e valente, deixai o amor à vida ao combater com os homens.

Não fujais, abandonando os mais velhos, que já não têm

Os joelhos prontos, os pobres anciãos.

Neste passo se vê que é mester dos jovens darem o peito à batalha, formando um todo solidário com o corpo do seu exército, com o dever de compensar pela sua força a fraqueza dos mais velhos. Todavia, estes estão lá, no campo de batalha, quando a crise a isso os chama.

O direito positivo organiza-se normativamente a partir de uma fonte inspiradora - Dike, que lhe assiste e que assiste à própria dinâmica da natureza, nos seus fundamentos sagrados. Mas quando o direito positivo se dissocia e se esquece da grande referência que o inspirou, o entendimento das leis daquele empobrece e torna-se redutor. No que à geroboskia diz respeito, como se viu no início deste trabalho, o entendimento do homem é olhá-la baseada num princípio ético de incessante reciprocidade - que projecta sobre o próprio mundo animal. Haverá uma demarcação nítida do domínio da obrigação da paidotrophia e da passagem para o domínio dos deveres de geroboskia, de modo a poder dizer-se que quando uma se inicia a outra acaba? O modo como Sófocles formulou poeticamente a lei vigente entre as aves, no estásimo III de Electra, sugere, pela construção, uma imbricação de ambos os deveres, numa espécie de interacção sem tempo. A assistência mútua entre pais e filhos parece ser aquela que as leis da natureza e as necessidades do momento impõem.

Eurípides, por sua vez, parece querer demonstrar que o segredo de articulação de ambas, para além da legislação vigente na pólis, reside, essencialmente, na interacção de uma incessante philia. É esta que confere sentido aos gestos de

17 Tradução de M. H. Rocha Pereira. 
solidariedade. Aliás, Cantarella ${ }^{18}$ recorda a realidade que passava ao lado da lei, como o caso de um tal Sopeu, pai de um cliente de Isócrates, que, na velhice, continuava a apoiar financeiramente o seu filho para que este se expandisse no comércio marítimo.

Os laços de philia mais fortes, na casa de Admeto, são os que o unem a uma "estrangeira e, contudo, necessária à casa" (533). Assim o explica ele mesmo ao hóspede que acolhe, apesar do seu luto - outro estrangeiro, com quem os laços de philia, gerados pelo acolhimento nas presentes circunstâncias dramáticas (gesto que, segundo o Coro, demonstra to eugenes de Admeto, 600) se consolidam e levam à retribuição de favores, por parte de Héracles. Ao trazer Alceste de volta do Hades, Héracles manifestou, por sua vez, a sua nobre natureza de amigo grato (eugenes, 1136) e, como Admeto reconhece (1138): “...foste somente tu quem reegueu a minha casa".

Entre o acolhimento de Héracles e o seu gesto de gratidão situa-se o agon Admeto/Feres. Admeto é tratado por todas as personagens como um rei que merece respeito, excepto por seu pai, Feres ${ }^{19}$. Este, em contrapartida, foi já alvo, ainda sem estar presente no palco, da referência sem simpatia de Apolo, da crítica de Alceste, de Admeto e do Coro.

A primeira intervenção de Feres, após as críticas antecipadas à personagem, foi, certamente, recebida pelo público como uma manifestação de cegueira egoísta ou de cinismo. No contexto das honras fúnebres Feres saúda a jovem morta como uma mulher nobre e prudente (esthles ... kai sophronos/ gynaikos, 615-616), que evitou fazer de Feres um homem idoso sem filhos. Ao saudá-la como alguém que "nos reergueu da ruína" (625-626), o pai de Admeto deixa a impressão de que a ruína a que se refere é a sua própria, de pai idoso sem filhos. Finalmente reconhece que este é o tipo de casamento vantajoso - outro não valeria a pena (627-628).

Esta conclusão contrasta com a demonstração do valor e da força dos laços entre os esposos - realidade bem mais forte do que o próprio Admeto pensaria e de que está a tomar dolorosa consciência no presente. $\mathrm{O}$ discurso inicial de Feres está, todo ele, centrado no próprio Feres. Ele mostra-se como alguém apenas disposto a receber favores. Na resposta a Admeto os motivos desta atitude serão formulados: a sua tarefa no oikos, isto é, os seus deveres ético-cívicos mais elementares cessaram: houve um tempo para os cumprir — o de gerar um filho, um herdeiro do património, mas a partir daí, reconhece, como acima se notou (685-686), que o filho está a sós com o seu destino, seja ele propício ou desastroso: “o que tinhas a receber de nós já o possuis". Feres refere-se, certamente, ao dom da vida, viabilizada pela educação e pelo alimento, pois só de seguida mencionará o

\footnotetext{
${ }_{18}$ Cantarella 2015: 8.

19 Smith 1968.
} 
património que Admeto receberá um dia. Tal perspectiva redutora, por parte do progenitor, leva-o a entrar em contradição. O sentido da perpetuação da casa foi ameaçado pelo próprio apego à vida, por parte de Feres, que se sobrepôs a tudo. Chegou o seu tempo de receber favores e cuidados. Alceste, com a sua morte, assegurou que esse direito ficasse salvaguardado. Nesse aspecto, Feres contrasta com o velho Iolau de Heraclidas que, na sua velhice, não hesita em tomar sobre os seus ombros a tarefa desproporcionada de cuidar da descendência de Héracles.

É nestas circunstâncias que Admeto repudia o progenitor, pela sua apsychia (642), e nega a sua ligação aos pais. Quebrados os laços de solidariedade, sacrificada a aliança matrimonial sobre a qual assenta a fecundidade do oikos por culpa do egoísmo de anciãos, Admeto vê o pai como a verdadeira causa da desagregação desse oikos, não como instituição que se perpetua - pois já existe descendência - , mas como espaço de harmonia e fonte de eudaimonia. Estes valores são possíveis quando é possível manter a aliança homem-mulher, celebrada pelo casamento, como pilar da casa. É isto o que Admeto aprende com a perda de Alceste, para compreender o valor daquilo que recupera, graças à philia de um estranho à casa, de excepcional capacidade. A expectativa de Feres é, sem dúvida, ter garantida a assistência na velhice. Admeto sente-se desvinculado dessa obrigação: nas palavras de repúdio que profere em relação ao pai, e que incluem, obviamente, também a mãe (658-668), nega-lhes os cuidados fúnebres que estão, por lei, a cargo dos filhos, e convida-os a procurar outra fonte de geroboskia (663), já que os vínculos de solidariedade foram destruídos, já que o sentido de interacção familiar nada significou para Feres, encerrado na sua expectativa de quem tem direito a receber favores, porque o tempo de os prestar já terminou. No mesmo discurso Admeto proclama-se, espontaneamente, adoptável como filho por aquele de quem recebeu favores e a quem servirá, na velhice, de philon gerotrophon (668) - Héracles.

Uma espécie de transferência de vínculos de família ocorrerá também, como se disse, no Coloneus. A maldição que Édipo faz recair sobre os filhos, convertendo-se de seu antigo paidotrophos em força mortífera de destruição de vida e da casa, decorre da parcial quebra de solidariedade da sua casa para consigo, originando uma peculiar relação de geroboskia: a praticada pelos elementos femininos e não masculinos ${ }^{20}$, e que, segundo o amargo comentário de Édipo, não obedece a normas gregas, mas egípcias ${ }^{21}$. Em contrapartida, Édipo torna-se voluntariamente garantia de vida e de perpetuação para Atenas, que o acolheu sem reservas na velhice e no sofrimento.

Em Alceste a cadeia de cuidados quebrou-se por parte dos mais idosos. Aberta fica a possibilidade, nestas duas peças que se distanciam em mais de

\footnotetext{
${ }^{20}$ Rosenmeyer 1952: 92-112; Fialho 1992: 107-156.

${ }^{21}$ Neste passo (OC 337-338) é reconhecida a influência de Heródoto 2. 35.
} 
vinte anos, de consolidação de laços mais fortes que os familiares, na sequência de uma demonstração de philia com a força da solidariedade que se sobrepõe aos laços da physis. E essa philia pode representar uma verdadeira fonte de vitalização e reforço para a instituição oikos e, em última análise, para a pólis.

O reconhecimento do papel ético-político da amizade, que Aristóteles fará na sua Ética a Nicómaco, aparece antecipado na tragédia grega (incluindo Alceste, independentemente de poder ser considerada tragédia). Nesta peça Eurípides parece ter querido chamar a atenção, no conflito geracional Admeto/ Feres, para os limites do entendimento das relações dentro da casa, quando estas se reduzem ao cumprimento de um estatuto e esquecem a fonte natural que dá sentido a esse estatuto. $\mathrm{O}$ alimento em causa, que os pais concedem aos filhos e os filhos aos pais, não pode estar sujeito a prazos nem ser entendido como mera educação ou nutrição. Esse alimento é a própria vida revivificada pela constante interaç̧ão da solidariedade e dos afectos. A grande ameaça que põe em perigo este entendimento é o egoísmo e o individualismo que, em última análise, podem destruir casas e conduzir a pólis a uma crise profunda. Mas, mais do que isso, Eurípides parece ter querido chamar a atenção para uma realidade do oikos, através da figura de Admeto, o seu kyrios, e das circunstâncias que o puseram à prova, a ele e às suas certezas, a ele e ao seu apego à vida, no centro da casa: a casa não pode ser entendida como uma entidade absolutamente fechada, pois não se alimenta nem perpetua a si mesma. A peça de Eurípides dramatiza a consciencialização do valor dos afectos, no oikos, e da suprema importância da harmonia entre os esposos, recuperada e fortalecida com o regresso de Alceste. É esse o fulcro da vitalidade e perpetuação do oikos, não meramente biológica, mas de dimensão ética. Deve ser esse o fulcro integrador da relação entre todos os membros da casa: aqueles que estão unidos por laços do mesmo sangue e aquele que entra de novo e assegura a continuidade da instituição que o acolhe. É da solidez desses laços que a casa se alimenta e alimenta todos os seus membros.

É nesse contexto que todos devem estar atentos à interacção que deles se espera, é nele que ganha sentido a própria geroboskia, como um dos vínculos entre outros, sem que a constante disponibilidade de sacrifício mútuo, pelo afecto e pela coesão da comunidade oikos, seja esquecida. Admeto sabe, após a perda e a recuperação de Alceste, que a sua existência, ainda que como senhor da casa, não vale por si. À prova foi posto o afecto e a abnegação paternas. Quanto a eles, Admeto está só, ainda que vivo para administrar os seus bens e tutelar os seus descendentes. E essa vida, como senhor da casa, sente-a, afinal, esvaziada de qualidade. Aparentemente tarde demais, como um herói trágico — que não é - na sua queda, Admeto reconhece (939-940):

Mas eu, que não devia estar vivo, escapei ao meu destino para enfrentar uma penosa existência: agora o compreendo! 
Uma vez reconhecida a estrangeira velada que Héracles traz consigo, pondo à prova Admeto, o senhor da casa regressa também à vida, ao exclamar: O philtates gynaikos omma kai demas (1133).

Comparando a atitude de Feres com a de Iolau, em Heraclidas, o contraste é nítido: o parente já envelhecido de Héracles é a única pessoa que se presta, para além das suas forças, a guiar e proteger os filhos órfãos de Héracles, perseguidos pela ira de Euristeu. Iolau está cansado, como se espera da sua idade; não tem, necessariamente, de desempenhar o papel que assume - fá-lo, como diz, pelos valores de to syngenes, a ponto de não hesitar em pegar em armas. É óbvio que já não lhe compete combater, na sua idade. Mas a solidariedade e a compaixão apelam a gestos excepcionais. Nem velhos nem novos estão excluídos do imperativo de solidariedade que mantém coeso o oikos. Ainda que impotente, Anfitrião, em Héracles, tem papel tutelar perante a família do herói ausente e ameaçada. Anfitrião, tal como Feres, confessa o seu amor à vida. Mas expõe-se, no perigo, invocando a parte de paternidade que lhe toca quanto a Héracles. Há então uma idade para que cessem deveres e apenas prevaleçam direitos? Em nome da integridade do oikos, o princípio que dá sentido ao cuidado é a solidariedade, a philia, capaz do sacrifício. Ela pode estar adormecida em tempo de paz, mas em tempos de crise não há parente, não há cidadão a quem não toquem direitos e deveres, ainda que a idade seja avançada e o Hades não seja apelativo. Parece ser esta a conclusão de Eurípides ${ }^{22}$.

E a Guerra do Peloponeso, na sua fase final, parece vir abrir outros horizontes à solidariedade: morto um número incontável de guerreiros/cidadãos no mar ou em terra, em campo de batalha, quem zelará pelos pais, na velhice? Em Édipo em Colono é a linha feminina que de tal se ocupa. Em Ifigénia em Áulide, a jovem princesa interpela seu pai, tentando que este lhe poupe a vida (1228-1230):

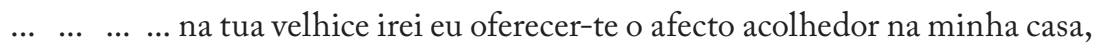
meu pai, e retribuir-te os cuidados desvelados com que me criaste?

Este é o eco, possivelmente, de uma nova realidade: a do após-guerra, em que a mulher é chamada a desempenhar funções do homem na cidade.

${ }^{22}$ Konstan 1997: 70 comenta, a partir do contexto de reflexão aristotélica sobre a amizade (EN 8): "Commonwealth for their parts arise out of a kind of accord, then, but family ties, which, though of various sorts (polueides, 1161b 17), derive ultimately from paternal philia (patrike), have another basis as well: for parents love children as being of themselves, and consequently love them as they love themselves". 


\section{Bibliografia}

Cantarella, E. (2015), “Gerotrophia: a controversial law”, in PDF 2015 file:/// Users/utilizador/Desktop/varia/Cantarella\%20english.pdf.html

Damet, A. (2015), "La mère athénienne, sujet des droits", Cahiers Mondes Anciens 6: http://mondesanciens.revues.org./1379

Fialho, M. C. (2010), "Paidotrophia and gerotrophia: reciprocity and disruption in Attic tragedy”, in Harris, E. M., Leão, D., Rhodes, P. J. (eds.), Law and drama in Ancient Greece. London, New York: 108-121.

Fialho, M. C. (1992), Luz e trevas no teatro de Sófocles. Coimbra: INIC.

Goldfarb, B. E. (1992), "The Conflict of Obligations in Euripides' Alcestis", GRBS 33: 109-126.

Harrison, A. R. W. (1968-1971), The Law of Athens. I-II. Oxford: Clarendon Press.

Hunter, V. (1994), Policing Athens. Social Control in the Attic Lawsuits, 420-320 B. C. Princeton: University Press.

Kells, J. H. (1973, reimpr. 1993), Sophocles. Electra. Cambridge: University Press. Konstan, D. (1997), Friendship in Classical World. Cambridge: University Press.

Leão, D. F. (2001), Sólon. Ética epolitica. Lisboa: Fundação Calouste Gulbenkian.

Leão, D., Rhodes, P. J. (2015), The laws of Solon. A new edition with introduction, translation, commentary. London-New York: I. B. Tauris.

Lesky, A. (1972), Die tragische Dichtung der Hellenen. Göttingen: Vandenhoeck \& Ruprecht.

Luschnig, C. A. E. (1992), "Interiors. Imaginary Spaces in Alcestis and Medea", Mnemosyne 45: 19-44.

Patzer, H. (1945), Physis. Grundlegung zu einer Geschichite des wortes. Marburg: diss.

Rosenmeyer, Th. (1968), "The Chorus and Admetus", in Wilson, J. R. (ed.), Twentieth Century Interpretations of Euripides' Alcestis. London, PrenticeHall: 65-70.

Rosenmeyer, Th. (1968), "Heracles and Pheres" in ibidem: 71-79.

Segal, Ch. (1992), "Euripides' Alcestis: Female Death and Male Tears", Cl. Ant. 11: $142-158$.

Segal, Ch. (1981), Tragedy and Civilisation. Cambridge: Harvard University Press.

Smith, W. D. (1968), "The Ironic Structure in Alcestis", in Wilson, J. R. (ed.), Twentieth Century Interpretations of Euripides' Alcestis. London, PrenticeHall: 37-56. 
Stroud, R. (1979), The Axones and Kyrbeis of Dracon and Solon. Berkeley: University of California Press.

Thury, E. M. (1988), "Euripides' Alcestis in the Athenian Generation Gap”, Arethusa 21: 197-214.

Todd, S. C. (1993), The Shape of Athenian Law. Oxford: Clarendon Press. 